\title{
Effect of the grinding behaviour of coal blends on coal utilisation for combustion
}

\author{
F. Rubiera ${ }^{\mathrm{a}}$, A. Arenillas ${ }^{\mathrm{a}}$, E. Fuente ${ }^{\mathrm{a}}$, N. Miles ${ }^{\mathrm{b}}$ and J.J. Pis ${ }^{\mathrm{a}^{*}}$ \\ ${ }^{a}$ Instituto Nacional del Carbón. CSIC. Apartado 73. 33080 Oviedo. Spain. \\ ${ }^{\mathrm{b}}$ School of Chemical, Environmental and Mining Engineering. Nottingham University. NG7 \\ 2RD. United Kingdom.
}

\begin{abstract}
Grinding of a high volatile bituminous coal was performed in three comminution devices: Raymond Mill, Rolls Crusher and Ball Mill. The pulverised samples were sieved to obtain four particle size fractions and temperature-programmed combustion (TPC) was used for the evaluation of their combustion behaviour. In addition, three coals of different hardness and rank were mixed in various proportions in order to compare the combustibility characteristics of the binary coal blends with those of the individual coals. The effect of coal blending on grindability was also studied. It was found that grindability was non-additive especially when coals of very different Hardgrove Grindability Index (HGI) were blended. The combustion studies also suggested that there exist interaction between individual coals when they are burnt as a blend.
\end{abstract}

\section{Résumé}

Un charbon bitumineux contenant un taux élevé de matières volatiles a été broyé au moyen de trois types de broyeurs: un broyeur Raymond, un broyeur à rouleaux et un broyeur à boules. Les échantillons pulvérisés ont été tamisés pour obtenir quatre fractions de différent diamètres de particules et des essais de combustion à température contrôlée (TPC) ont été réalisés pour évaluer leur comportement pendant le processus de combustion. En outre, trois charbons de dureté et rang différents ont été mélangés en proportions variées, afin de comparer les caractéristiques de combustion des mélanges binaires à celles des charbons individuels. L'effet du mélange des charbons sur la capacité de mouture a été également étudié. On a trouvé que cette capacité n'est pas additive, surtout quand des charbons ayant des Indices Hardgrove (HGI) très différents sont mélangés. Les études de combustion montrent 
aussi qu'il existe une intéraction entre les charbons individuels quand ils sont brûlés en tant que mélange.

Keywords: Comminution; Hardgrove Index; Coal blends; Combustion

\section{Introduction}

Coal grindability is a complex property related to coal hardness, strength, tenacity, and fracture. All these properties are influenced by coal rank, petrography, and the type and distribution of minerals. The grindability of a coal blend, as measured by the Hardgrove Grindability Index (HGI), is of great interest since it is used as a predictive tool to determine the capacity of industrial pulverisers in coal-fired power stations. There have been some investigations on the HGIs of coal blends specifically in relation to the additivity of the HGI and although some coal blends show additivity this is not usually the case [1-3]. Thus, there is no general method for predicting the HGI of a coal blend, and hence, it must be determined experimentally on a case by case basis. This, in turn, makes it very difficult to set the grindability specification of the coals to be blended. Utilities are, in addition, switching to low-NOx combustion technologies and need to obtain a balance between the conflicting requirements of minimum NOx emissions and acceptable unburnt carbon levels in the fly ash [4]. This dependence of unburnt carbon and NOx emissions could potentially be minimised by grinding the coal finer which in turn will be dependant upon the method of comminution. In this respect there have been few studies carried out on the comminution of coal blends, and the resulting products, by different methods of crushing and grinding [5]. Thus a better understanding of the effects of the size distribution, Hardgrove Grindability Index and coal blending on pulverised fuel behaviour would be of great benefit.

Coal blending is of increasing interest to power stations firing pulverised coal, as operators attempt to increase the flexibility of fuel types, improve the combustion behaviour of their coals and meet the requirements of emission legislation. Some aspects of the combustion behaviour of blended coals in power station boilers are known, and can be determined reasonably well from knowledge of the properties of the component coals in the blend. However, the effects of firing blended coals on ignition behaviour, NOx emissions, burnout and the incidence of phenomena such as slagging and fouling cannot be so easily inferred by this approach, particularly if low NOx technologies are employed [6]. 
Additionally, the difficulties in burning low volatile coals and anthracites under NOx control conditions are well known. The increase in volatile species in the flame zone by blending these types of coal with high volatile coals can substantially reduce NOx emissions favouring, at the same time, the combustion behaviour of the higher rank coal.

The main objective of this work was to study the effect of coal particle size distribution on combustion behaviour with particular attention being given to the effect of mixing coals of different rank and varying Hardgrove Grindability Index. To this end four coals of varying rank from high volatile bituminous coal to anthracite were chosen as starting materials. One of the coals was ground in several comminution devices and dry screened to obtain different particle size fractions. A differential thermogravimetric system was utilised for the evaluation of the combustion behaviour of the single coals and their blends.

\section{Experimental}

\subsection{Sample preparation}

Three coals of varying rank from high volatile bituminous coal to anthracite were selected for the preparation of binary blends. Their proximate analysis is given in Table 1. LO and WI were USA coals while GI was a Spanish anthracite. A low ash content was another criteria used for the selection of the samples in order to minimise the effects of mineral matter. Preparation of binary coal blends for evaluation of combustion behaviour, involved grinding the individual coals in a mortar grinder to minus $150 \mu \mathrm{m}$ in size and dry sieving to obtain a 75-150 $\mu \mathrm{m}$ size fraction. The individual coals were mixed after grinding by varying the content of lower rank coal to generate three blends containing $25 \%, 50 \%$ and $75 \%$ by weight respectively.

The Hardgrove Grindability Index (HGI) was measured in accordance with standard procedures [7]. The HGIs of the binary coal blends were determined after mixing 0.60-1.18 $\mathrm{mm}$ size fractions in the proportions outlined above. 


\subsection{Comminution}

Three comminution devices - Raymond Mill (RM), Rolls Crusher (RC) and Ball Mill (BM) - were used to grind a UK high volatile bituminous coal (UK1). A representative sample was split from the bulk 2 tonne sample of $-50 \mathrm{~mm}$ material. This sub-sample was staged crushed in a jaw crusher set at $20 \mathrm{~mm}$ and then to $6 \mathrm{~mm}$. This material was then crushed in a rolls crusher set at $2 \mathrm{~mm}$. The above material was then split into three subsamples and comminuted in the following three devices:

Raymond Mill - This was a laboratory swing hammer mill fitted with an internal $212 \mu \mathrm{m}$ screen. Breakage was predominantly by impact of the hammers on the coal.

Rolls Crusher - This was a Strutevant double smooth rolls crusher, $102 \mathrm{~mm}$ in length and 203 $\mathrm{mm}$ in diameter. This crusher was set to its minimum gap of around $1 \mathrm{~mm}$ and the material fed through. The resultant product was screened on a $212 \mu \mathrm{m}$ sieve with the oversize re-crushed at the same set. The procedure was repeated 8 times.

Ball Mill - The coal sample was dry ground in a 305x305 mm laboratory ball mill. Total weight of steel ball charge was $31.6 \mathrm{~kg}$, which occupy $50 \%$ of the mill volume and comprising three ball sizes: $3.8 \mathrm{~cm}$ diameter $(24.8 \mathrm{~kg}), 5.1 \mathrm{~cm}$ diameter $(6.1 \mathrm{~kg})$ and $0.9 \mathrm{~cm}$ diameter $(0.7 \mathrm{~kg})$. The material was ground for 10 minutes and then sieved on a $212 \mu \mathrm{m}$ sieve.

The resulting products from each device were then dry sieved to generate the following discrete size fractions; $150-212 \mu \mathrm{m}, 75-150 \mu \mathrm{m}, 38-75 \mu \mathrm{m}$ and $<38 \mu \mathrm{m}$.

\subsection{Temperature-programmed combustion tests}

Temperature-programmed combustion profiles (TPC) were obtained using a differential thermogravimetric analyser (Setaram TAG 24). It is well known that the use of different equipment and operational conditions give significant variations in the results obtained by TGA. Experimental conditions leading to consistent reproducible results were already established from previous work [8,9]. In all experimental work approximately $25 \mathrm{mg}$ of coal and an air flow rate of $50 \mathrm{~cm}^{3} \mathrm{~min}^{-1}$ were used. The samples were heated at $15^{\circ} \mathrm{C} \mathrm{min}^{-1}$ from room temperature to $1200^{\circ} \mathrm{C}$. A number of parameters can be derived from TPC profiles and a typical combustion profile is shown in Figure 1. The rate of weight loss curve (DTG), the rate of heat flow curve (DTA) along with the main characteristic parameters that will be used in this work are displayed in Figure 1. These parameters are defined as follows: 
Tv Volatile matter initiation temperature. Calculated as the temperature where the rate of weight loss reached the value of $0.005 \% \mathrm{~s}^{-1}$ following the loss of moisture and oxygen chemisorption.

Tm Temperature of maximum rate of weight loss or peak temperature.

Rmax The reactivity value at the peak temperature.

T1/2 Temperature at $50 \%$ burn-off of organic material.

Te Temperature of char burnout. Calculated as the temperature where the rate of weight loss reached a value of $0.005 \% \mathrm{~s}^{-1}$.

tb Burnout time or time between Tv and Te.

Tsh Temperature of self-heating. Calculated from the DTA curve as the temperature where the rate of heat flow began to be exothermic.

Tec End of combustion temperature. Calculated as the temperature where the rate of heat flow passed from exothermic to endothermic.

\section{Results and discussion}

\subsection{Effect of comminution on coal combustion behaviour}

Temperature-programmed combustion tests were conducted on the 12 coal samples obtained from the comminution devices. These results are presented in Figure 2 as a series of curves showing the variation of the rate of weight loss against temperature. The most relevant characteristic parameters from the TPC profiles are given in Table 2.

It can be seen from Figure 2 a shift of the curves to higher temperatures as the particle size increased. The volatile initiation temperature, $\mathrm{Tv}$, increased as did the particle size; this corroborates the well-known poorer ignition and burning behaviour encountered with larger particle sizes. Other temperatures such as $\mathrm{Te}, \mathrm{Tm}$ and $\mathrm{T}_{1 / 2}$ were even more affected by an increase in particle size. For instance, in the case of the Rolls Crusher the temperature Te, passed from $621^{\circ} \mathrm{C}$ for the smallest fraction $(-38 \mu \mathrm{m})$ to $729^{\circ} \mathrm{C}$ for the largest fraction $(150$ $212 \mu \mathrm{m})$. The increase in these parameters along with that of the burnout time, tb, also indicated that the fine particles required lower residence times and temperatures to achieve complete combustion. 
Another feature that can be observed in Figure 2 is the stage of oxygen chemisorption, which occurred after the loss of moisture. There was in all cases a net increase in the amount of chemisorbed oxygen with decreasing particle size. This was a consequence of the increase in the external surface area of the finer particles with more active sites exposed to the action of the reactive gases.

The self-heating temperature, Tsh, is often regarded as an indicator of the susceptibility of coal to self-heating and spontaneous ignition. It has been observed to increase with decreasing coal rank, with lignite and subbituminous coals being more susceptible to self-heating than bituminous coals and anthracites $[8,10]$. As can be seen in Table 2 the temperatures of selfheating generally increased in the samples from the Rolls Crusher and Raymond Mill. However the values for the material from the Ball Mill are slightly lower and fairly constant over the various size ranges at a value of around $191^{\circ} \mathrm{C}$. Nevertheless, these Tsh values were relatively low which means that there might be some risk of spontaneous combustion if there was a high proportion of fine material in stockpiles of this coal. The possible hazardous effects such as fires and explosions in the milling systems are another matter of concern [11].

A relative ranking in terms of combustibility can be established from the above results. Usually the burnout temperature, Te, and the maximum reactivity, Rmax, are taken as indicators of combustion behaviour for comparative purposes. From Figure 2 it can be observed that the samples obtained from the Ball Mill were more reactive and exhibited a better combustibility than those from the Rolls Crusher which, in turn, were better than those from the Raymond Mill. The reasons for this are unclear but may be a function of the detailed particle size distributions of all the products and the associated quantities of mineral matter present in the discrete size fractions.

Another feature observed in the 150-212 $\mu \mathrm{m}$ size fractions, particularly those from the Rolls Crusher and Raymond Mill (Figure 2), was the preliminary peak that appeared before the peak temperature. The preliminary peak is due to the combustion of volatiles, which occur at the surface of the material, and the reaction is not sufficient to sustain the combustion of the char, with two peaks appearing in the combustion profiles. The presence of this peak in the 150-212 $\mu \mathrm{m}$ fraction may be explained as a consequence of the segregation of macerals among the size fractions, with a tendency for the liptinite macerals, which yield the greatest amount of volatiles, to concentrate to the coarser size fractions [12]. Similarly, the 
agglomeration of particles due to the development of thermoplasticity has also been suggested as a cause of the preliminary volatiles evolution peak [13]. It was then decided to carry out additional combustion tests on the samples that exhibited the volatiles combustion peak. These 150-212 $\mu \mathrm{m}$ size fractions were re-ground to minus $75 \mu \mathrm{m}$ and the results for the material from the Rolls Crusher are illustrated in Figure 3. It can be seen that the combustion profiles of the re-ground fraction was different to that of the original one, with the disappearance of the preliminary volatiles combustion peak. The profile for the $38-75 \mu \mathrm{m}$ fraction from the Rolls Crusher has been also included in Figure 3 for comparative purposes. It can be observed that the resultant combustion profile of the re-ground fraction clearly resembled that for the 38-75 $\mu \mathrm{m}$ sample and not the original $150-212 \mu \mathrm{m}$ fraction. It can be concluded that although swelling of the larger particles may have taken place, the volatile evolution peak was a function of the coarser particle sizes.

\subsection{Grindability and combustion behaviour of coal blends}

The effect of mixing coals of different hardness and rank on the HGIs and combustion behaviour of the blends, in comparison with those of the individual coals, was also studied. Three different rank coals (see Table 1) were used for these tests. HGI data of the single coals and the blends are shown in Figure 4. Coals GI and LO were hard coals according to their HGIs of 34 and 47 respectively, whilst coal WI was a soft coal with a HGI of 91. From the results represented in Figure 4 it can be seen that the HGIs are highly non-additive when considering the blends of soft and hard coals (WI/LO and WI/GI). This is in disagreement with the results found by others using the same type of blends [3]. The blend made up of the two hard coals (GI/LO) showed a more linear relationship. Nevertheless, in all cases the HGI of the blend could not be predicted from the individual HGI of a coal and the weight fractions used in the blends. It is apparent that there was a preferential shift of the HGI of the blend towards higher values than would be expected from the linear additive rule. This indicates that when grinding blends comprising the individual coals of WI and LO or WI and GI there will be a segregation of the LO and GI coals to the smaller size fractions. From a practical point of view this could have important implications in the combustion behaviour of blends made from these coals. For instance the blending of the coal LO with the anthracite GI could be desirable in order to favour the combustibility of the higher rank coal, GI, and to reduce NOx emissions by increasing the amount of volatile species in the flame zone. The fact that 
grindability is non-additivite could produce a blend from the industrial pulveriser that is out of specification to that previously established.

The combustion behaviour of the three coals and their blends was evaluated by temperature-programmed combustion tests. Binary coal blends were prepared using the 75$150 \mu \mathrm{m}$ size fractions of the individual coals. The use of a relatively large particle size fraction, $75-150 \mu \mathrm{m}$, is of significance for predicting combustion behaviour, especially carbon burnout. Most current analysis techniques assess bulk properties, but for burnout prediction the behaviour of only a small fraction of particles, the 'least-likely-to-burn' or LLB fraction, is considered more relevant [14].

The results of the combustion tests for the LO/GI coal blends are shown in Figure 5. It can be seen that the volatile initiation temperature increased as the anthracite (GI) content in the blend increased. The maximum temperature remained closer to the peak temperature value of the coal with a higher percentage in the blend. However, at $50 \%$ by weight of anthracite in the blend it was possible to distinguish, in the zone of char combustion, the burning of the coal, LO, from that of the anthracite. This behaviour differs from that found by others who reported that the burning profile of blends of coals of different rank showed two well resolved peaks [15]. In addition, the burnout temperature, Te, increased as the percentage of anthracite in the blend increased but its value was always lower than that of the anthracite. Similar results were obtained for the blends, WI/GI and LO/WI. This indicated that some interaction between the samples has occurred during temperature-programmed combustion tests.

\section{Conclusions}

Evaluation of the combustion behaviour of a high volatile bituminous coal, comminuted in three different devices, has indicated that the samples pulverised in the Ball Mill exhibited better combustibility characteristics than those obtained from the Raymond Mill and the Rolls Crusher. The reason for this is unclear but may be a function of the particle size distributions.

The HGI of binary coal blends could not be predicted from the weighted average of the HGIs of the individual coals in the blend. This was especially true in the case of mixing a soft anthracite with a hard coal. The HGI of the blend resembled that of the softer coal. This may have important implications in combustion performance as the feed to a pulverised-fuel power 
station using these type of blends could be quite different than specified. One potential method of avoiding this problem would be to blend the coals after pulverisation.

Temperature-programmed combustion tests carried out in this work with three binary coal blends suggested that the coals burn with interaction. The combustion profile and the characteristic parameters of the blends could not be predicted from the data of the individual coals.

\section{Acknowledgements}

Work carried out with a financial grant from the European Coal and Steel Community (Project 7220-EA/133).

\section{References}

[1] J.C. Hower, J. of Coal Quality, 7 (1988) 68.

[2] R.E. Douglas, M.C. Mai and R.D. Stoessner, Proceedings 12th Int. Pittsburg Coal Conference, (1990) pp. 837-851.

[3] A. Waters, J. of Coal Quality, 5 (1986) 33.

[4] H. Maier, H. Spliethoff, A. Kicherer, A. Fingerle and K.R. Hein, Fuel, 73 (1994) 1447.

[5] S.F. Scieszka, Powder Technol., 49 (1987) 191.

[6] J.P. Smart, J.P and T. Nakamura, J. Institute of Energy, 6 (1993) 99.

[7] ASTM D 409, Standard test method for grindability of coal by the Hardgrove-Machine method.

[8] J.J. Pis, G. de la Puente, E. Fuente, A. Morán and F. Rubiera, Thermochimica Acta, 279 (1996) 93.

[9] F. Rubiera, A. Morán, O. Martínez, E. Fuente and J.J. Pis, Fuel Proc. Technol., 52 (1997) 165. 
[10] J.M. Kuchta, V.R. Rowe and D.S. Burgess, Report Invest. U.S. Bureau of Mines, No. 8474 (1980).

[11] D.H. Scott, Coal pulverisers-performance and safety, IEA Coal Research, IEACR/79, London (1995).

[12] A. Davis and P.C. Orban, Proceedings 12th International Pittsburg Coal Conference, (1995) pp. 312-317.

[13] J.B. Milligan, K.M. Thomas and J.C. Crelling, Fuel, 76 (1997) 1249.

[14] J.R. Gibbins and J. Williamson, Proceedings 7th International Conference on Coal Science, Banff, Canada, (1995) Vol. 1, pp.35-38.

[15] J.W. Cumming, Thermochimica Acta, 155 (1989) 151. 
Table 1. Main characteristics of the coals used for the preparation of binary coal blends.

\begin{tabular}{llll}
\hline Coal & LO & WI & GI \\
\hline Proximate Analysis & & & \\
Moisture (wt \%) & 1.4 & 0.7 & 3.0 \\
Ash (wt \%, db) & 6.7 & 8.0 & 9.3 \\
V.M. (wt \%, db) & 34.1 & 17.4 & 3.8 \\
F.C. (wt \%, db) & 59.2 & 74.6 & 86.9 \\
C.V. (kcal/kg, db) & 7839 & 8037 & 7396 \\
Hardgrove Index & 47 & 91 & 34 \\
\hline
\end{tabular}

(db: dry basis) 
Table 2. Characteristic parameters from temperature-programmed combustion tests for the different size fractions obtained from the three comminution devices.

\begin{tabular}{|c|c|c|c|c|c|c|c|c|c|}
\hline \multirow{2}{*}{$\begin{array}{c}\text { Size } \\
\text { Fraction } \\
(\mu \mathrm{m})\end{array}$} & \multirow{2}{*}{$\begin{array}{l}\text { Comminution } \\
\text { Device }\end{array}$} & \multirow[t]{2}{*}{$\begin{array}{c}\mathrm{TV} \\
\left({ }^{\circ} \mathrm{C}\right)\end{array}$} & \multirow[t]{2}{*}{$\begin{array}{l}\mathrm{Tm} \\
\left({ }^{\circ} \mathrm{C}\right)\end{array}$} & \multirow[t]{2}{*}{$\begin{array}{c}\mathrm{Te} \\
\left({ }^{\circ} \mathrm{C}\right)\end{array}$} & \multirow[t]{2}{*}{$\begin{array}{l}\mathrm{T}_{1 / 2} \\
\left({ }^{\circ} \mathrm{C}\right)\end{array}$} & \multirow[t]{2}{*}{$\begin{array}{l}\mathrm{tb} \\
(\mathrm{s})\end{array}$} & \multirow[t]{2}{*}{$\begin{array}{c}\mathrm{R}_{\max } \mathrm{x} 10^{2} \\
(\% / \mathrm{s})\end{array}$} & \multirow[t]{2}{*}{$\begin{array}{l}\text { Tsh } \\
\left({ }^{\circ} \mathrm{C}\right)\end{array}$} & \multirow[t]{2}{*}{$\begin{array}{l}\text { Tec } \\
\left({ }^{\circ} \mathrm{C}\right)\end{array}$} \\
\hline & & & & & & & & & \\
\hline \multirow{3}{*}{$150-212$} & $\mathrm{RC}$ & 325 & 532 & 729 & 556 & 1595 & 8.95 & 221 & 730 \\
\hline & $\mathrm{RM}$ & 325 & 544 & 745 & 561 & 1657 & 8.36 & 214 & 748 \\
\hline & $\mathrm{BM}$ & 324 & 544 & 732 & 559 & 1606 & 8.78 & 194 & 738 \\
\hline \multirow{3}{*}{$75-150$} & $\mathrm{RC}$ & 322 & 523 & 717 & 540 & 1561 & 8.71 & 194 & 722 \\
\hline & $\mathrm{RM}$ & 320 & 523 & 741 & 552 & 1658 & 8.60 & 216 & 743 \\
\hline & $\mathrm{BM}$ & 315 & 514 & 685 & 529 & 1457 & 9.89 & 192 & 689 \\
\hline \multirow{3}{*}{$38-75$} & $\mathrm{RC}$ & 313 & 519 & 674 & 524 & 1424 & 10.30 & 195 & 677 \\
\hline & $\mathrm{RM}$ & 316 & 519 & 706 & 519 & 1537 & 9.33 & 206 & 707 \\
\hline & $\mathrm{BM}$ & 302 & 495 & 640 & 496 & 1333 & 10.88 & 188 & 646 \\
\hline \multirow{3}{*}{-38} & $\mathrm{RC}$ & 299 & 485 & 621 & 484 & 1268 & 11.87 & 186 & 630 \\
\hline & $\mathrm{RM}$ & 301 & 485 & 622 & 484 & 1267 & 11.94 & 193 & 624 \\
\hline & BM & 298 & 469 & 600 & 468 & 1192 & 12.11 & 191 & 604 \\
\hline
\end{tabular}




\section{List of Figures}

Figure 1. Typical combustion profile showing characteristic parameters.

Figure 2. Comparison between the combustion profiles of the different size fractions obtained in the crusher and the two mills.

Figure 3. Combustion profiles of the 38-75 $\mu \mathrm{m}, 150-212 \mu \mathrm{m}$ fractions from the Rolls Crusher and the re-ground material $(-75 \mu \mathrm{m})$.

Figure 4. Hardgrove grindability indexes of the individual coals and their blends.

Figure 5. Combustion profiles of blends of the coal LO and the anthracite GI. 


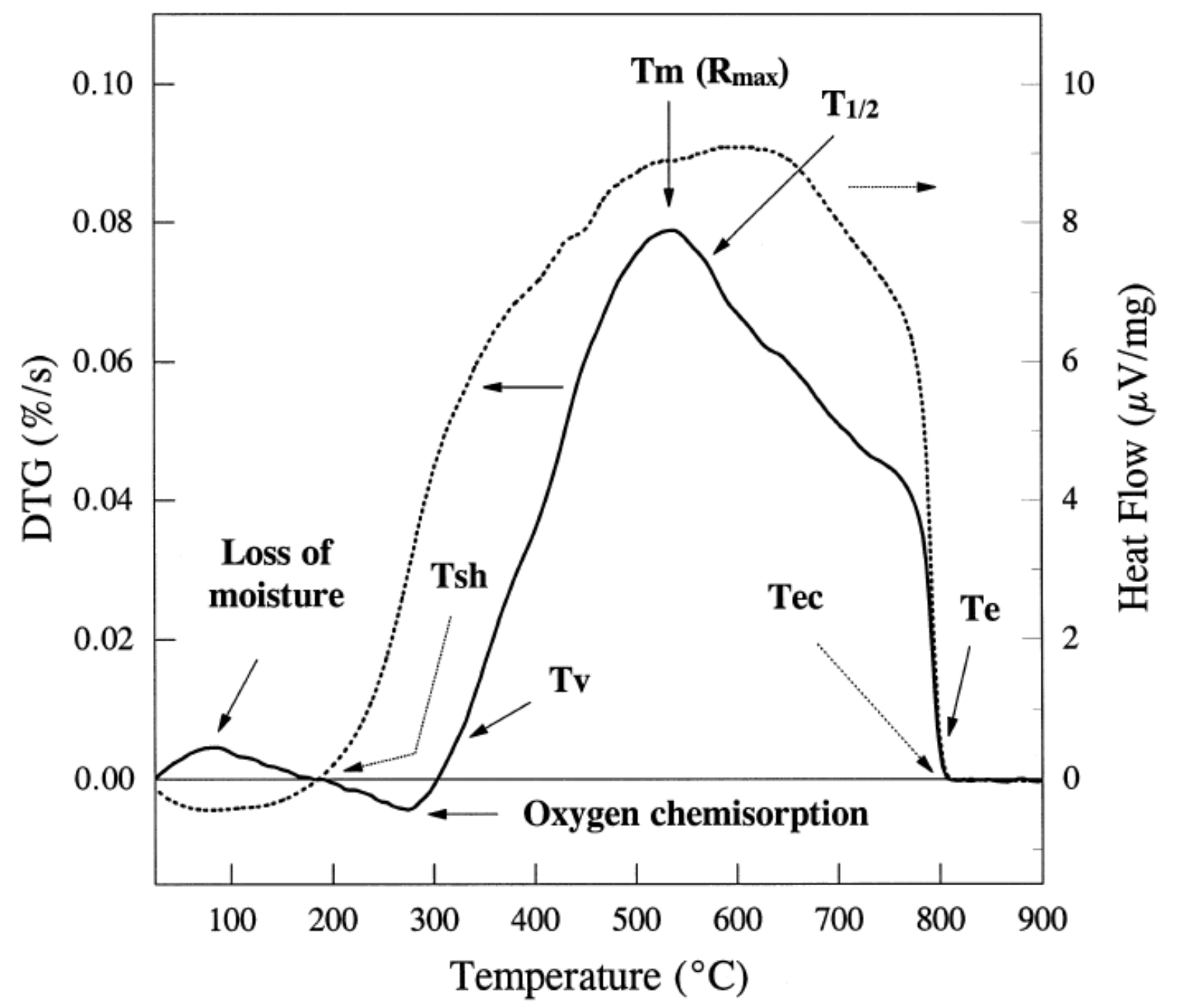

Figure 1. Typical combustion profile showing characteristic parameters. 

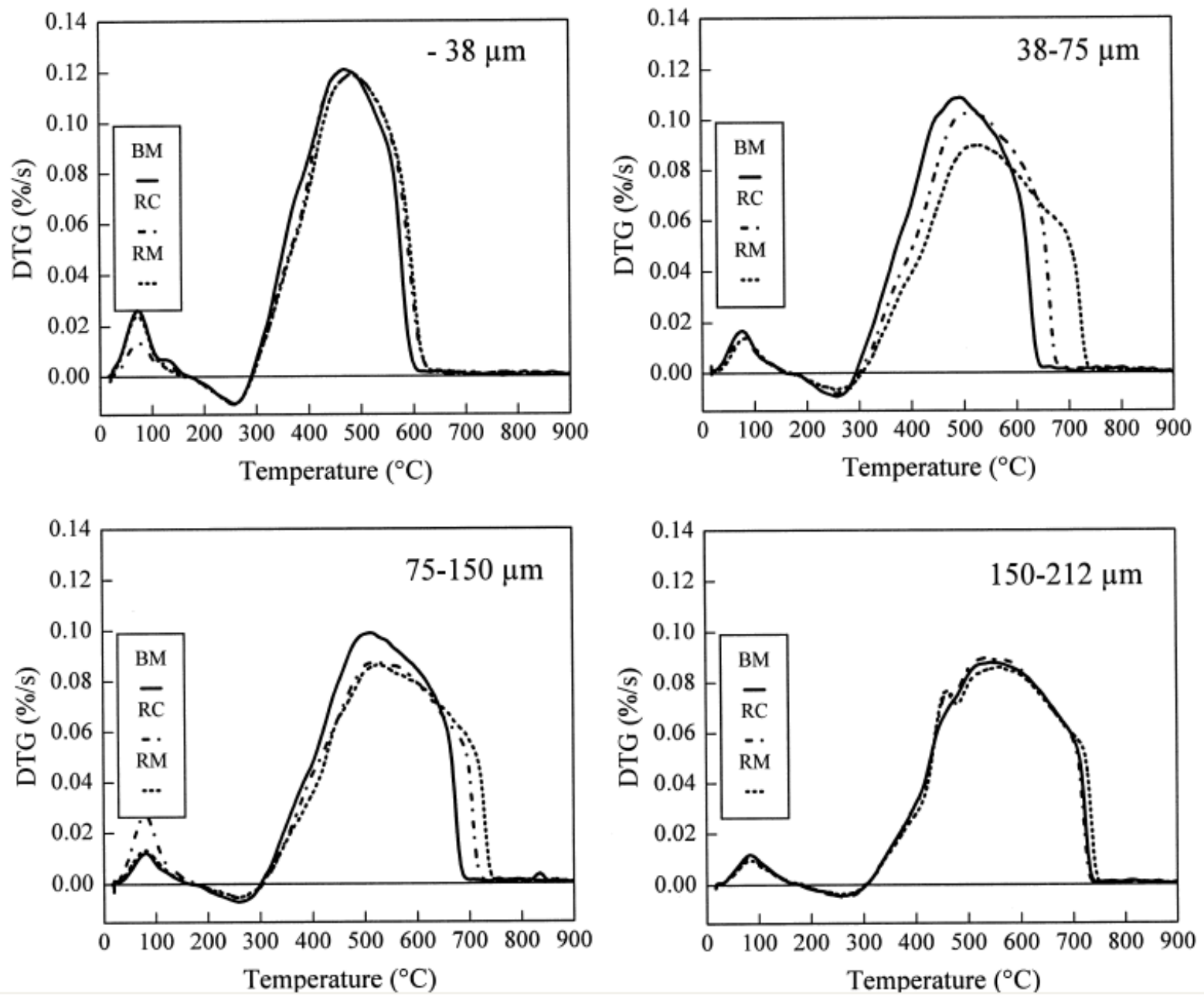

Figure 2. Comparison between the combustion profiles of the different size fractions obtained in the crusher and the two mills. 


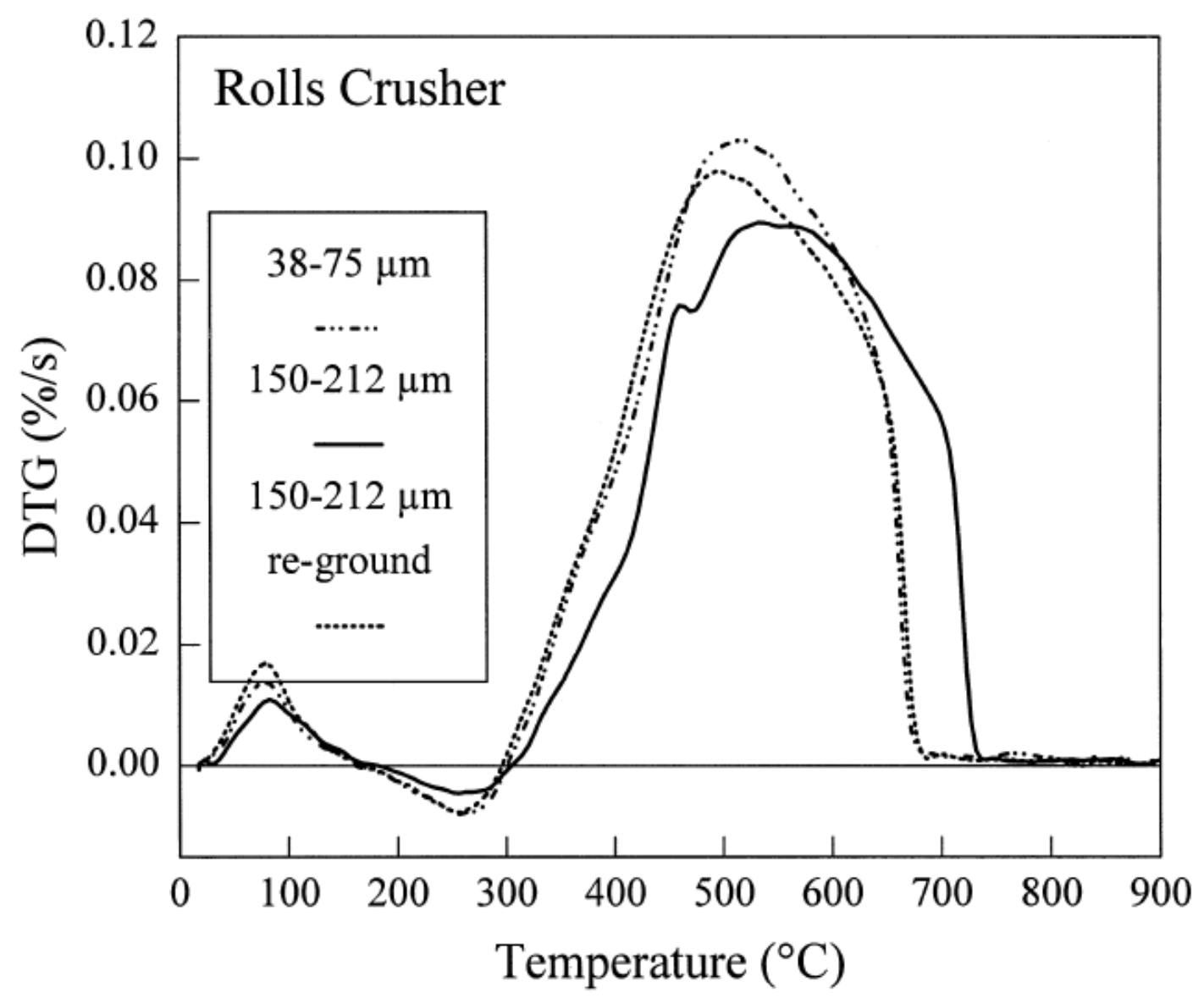

Figure 3. Combustion profiles of the 38-75 $\mu \mathrm{m}, 150-212 \mu \mathrm{m}$ fractions from the Rolls Crusher and the re-ground material $(-75 \mu \mathrm{m})$. 


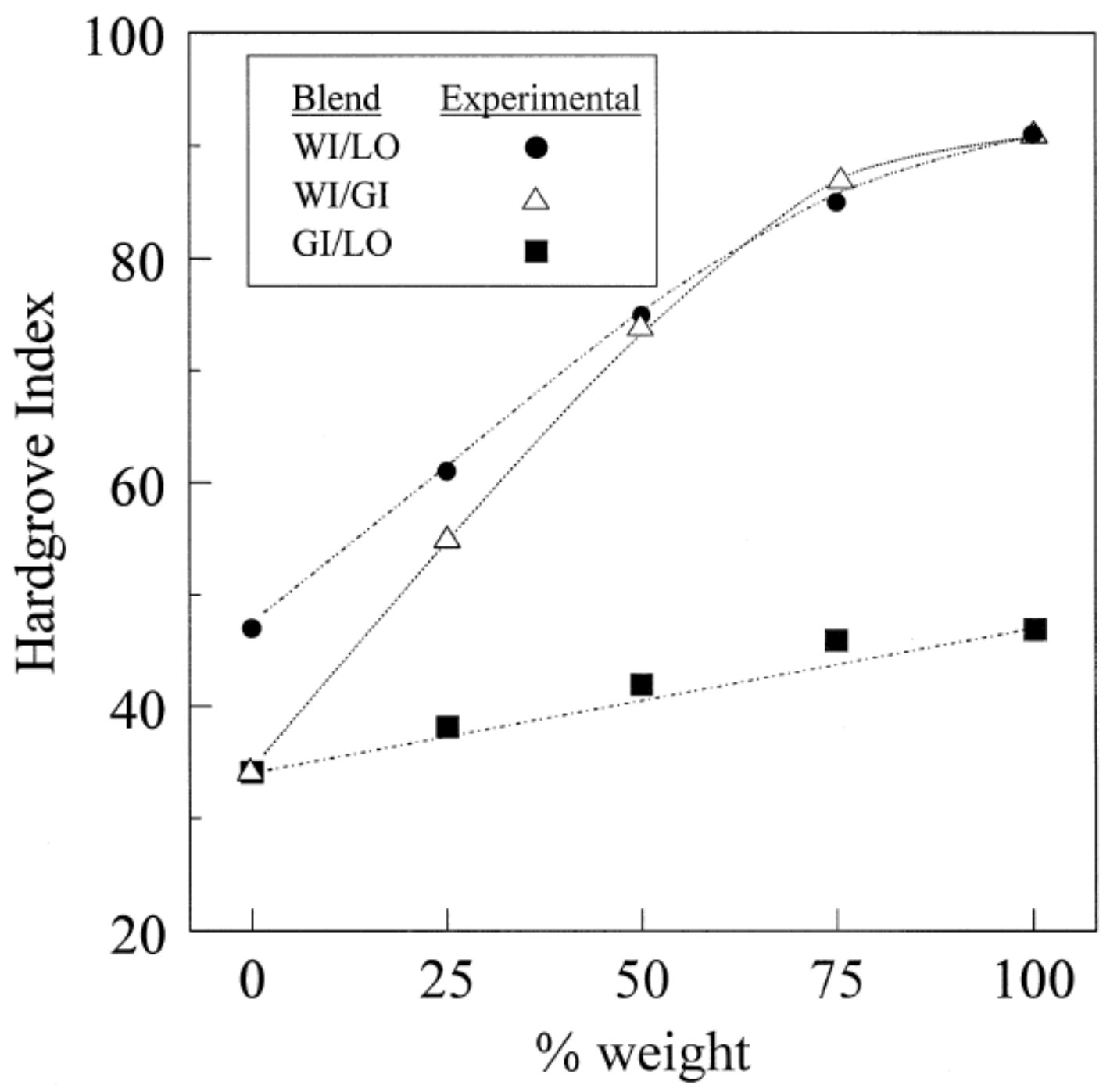

Figure 4. Hardgrove grindability indexes of the individual coals and their blends. 


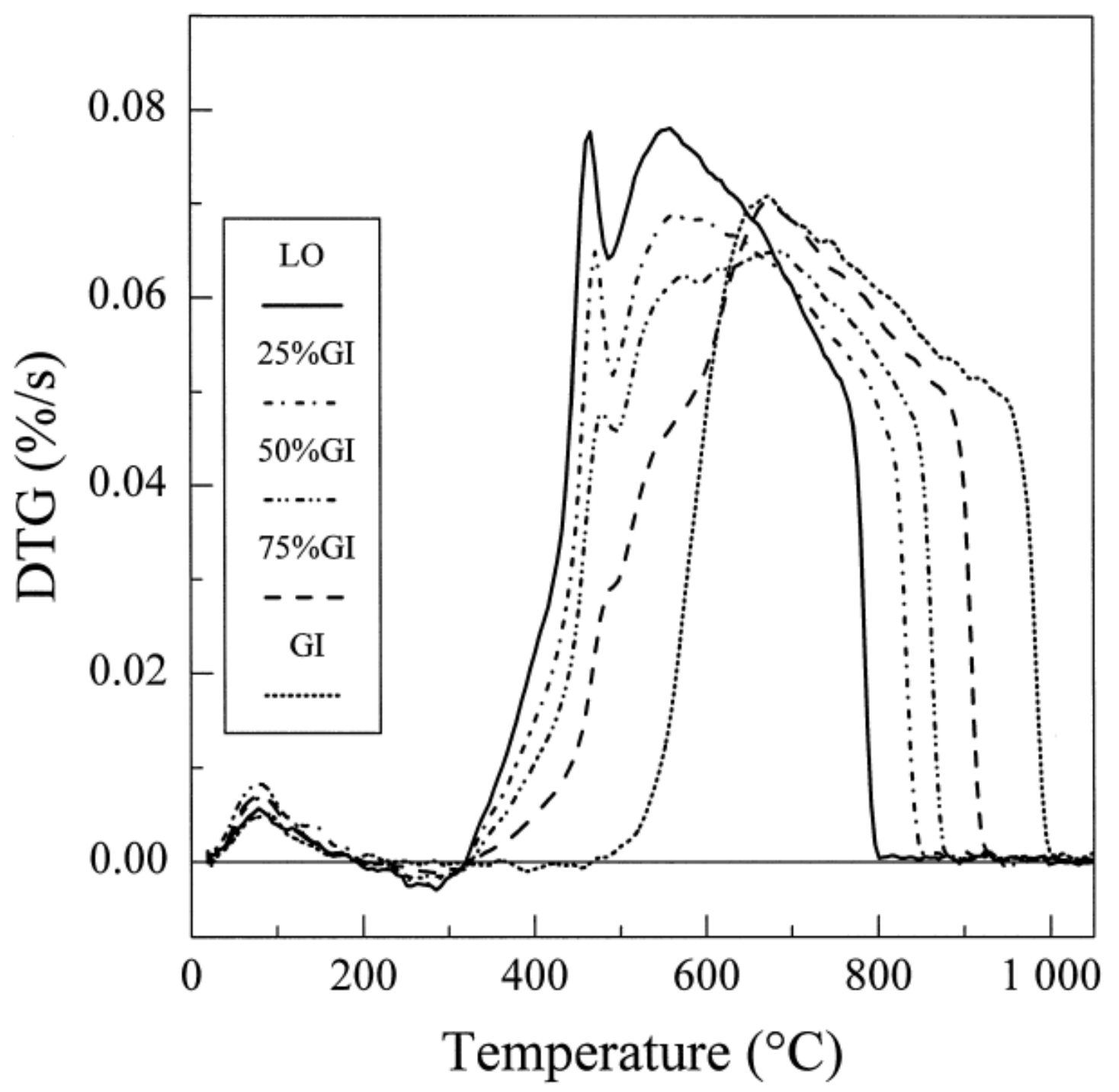

Figure 5. Combustion profiles of blends of the coal LO and the anthracite GI. 